support of his view. Unfortunately, as Prof. Arnold has pointed out, the heating curves actually show the Ac2 change. It is true that they are less strongly marked than the Ar2 changes, but this is only what would be expected.

The changes during heating, as shown by inverse rate curves, extend over a greater range and are therefore less strongly marked than in the cooling curves. This is well shown in the $\mathrm{A}_{3}$ change shown in the curves, and in view of the fact that the Ar2 change is itself very small, it was scarcely to be expected that the Ac2 change would be very easily detected. Moreover, Prof. Carpenter has shown that if the iron, after cooling just below $\mathrm{Ar}_{3}$, is held at that temperature for two and a half hours in order to allow the change from $\gamma$ to $a$ iron to become complete, and then slowly cooled, the Ar2 change is shown as decidedly as before. He attempts to explain this by assuming that the impurities present are sufficient to prevent actual contact of the $\gamma$ and $\alpha$ molecules, but the explanation is unsatisfactory, and his results must be regarded rather as proving than disproving the independence of the $A_{2}$ critical point.

The paper by Dr. Rosenhain and Mr. Humfrey describes a series of experiments admirably conducted with the aid of an ingeniously constructed testing machine, in order to investigate the physical properties of mild steel at high temperatures. It is impossible to describe the experiments in detail, but the results show that the curve representing the tenacity at high temperatures consists of three branches corresponding to the $\gamma, \beta$, and $\alpha$ ranges of iron. Starting at $1100^{\circ} \mathrm{C}$., the tenacity increases as the temperature falls, until the Ar3 point is reached, when there is a rapid decrease in tenacity. This is followed by a further increase until Ar2 is reached, when there is another falling off in tenacity. The influence of the rate of strain is discussed, also the influence of varying size of crystals; and photographs are given to illustrate the types of fracture at different temperatures. The authors conclude that they find it difficult to reconcile their results with Benedicks's theory by which $\beta$ iron is regarded as a solution of $\gamma$ iron and $\alpha$ iron.

Prof. Arnold's contribution to the discussion when separated from side issues resolves itself into little more than a reassertion of his own theories, which he claims are supported by the two papers in question. The one useful criticism which Prof. Arnold makes has already been referred to, in which he points out that the Ac2 change is observable in Prof. Carpenter's curves.

The criticism of Dr. Rosenhain and Mr. Humfrey's paper is even less helpful. It is claimed that the authors' conclusions are of no value owing to their "erroneously presupposing that they are discussing results obtained from chemically pure iron rather than from their dead mild commercial steel." It is possible that the authors have underestimated the importance of the impurities in their steel and have pushed their conclusions a little too far, but they give full details of the material upon which their experiments have been carried out. and they malse no claim that their conclusions are final. Nevertheless, the authors have laid themselves open to some criticism inasmuch as they have chosen for their experiments a steel which, even from a commercial point of view, is of very poor quality.

As a matter of fact, the importance of the discussion has been exaggerated, and the two napers leave the $\beta$ iron theory verv much where it was before. The somewhat ill-defined $\mathrm{A}_{2}$ change and its relation to the phvsical properties of steel will still attract the attention of men of science who are anxious to dis- cover the truth. Other papers will be read and further discussions will take place, but in the meantime, and until further evidence is forthcoming, those who are wise will refrain from a too dogmatic insistence upon their own particular views.

THE ROYAL SOCIETY CONVERSAZIONE.

T $\mathrm{HE}$ annual June conversazione of the Royal Society was held in the rooms of the society at Burlington House on June II. As is usual upon such an occasion, various instruments and objects of scientific interest were exhibited. Most of these have been described already in the account of the May conversazione given in Nature of May I $_{5}$ (p. 273). Other exhibits are mentioned below :-

I) r. E. C. Pickering: Colour-blindness, if any, of eminent astronomers. The sensitiveness of the eve to rays of different colours has been tested for numerous astronomers by grouping their estimates of the light of the stars according to their colour, as shown by the class of spectrum. The earliest estimates, those of Ptolemy and Sûfi, show results agreeing closely with those of recent times. Peirce shows a marked sensitiveness to the red, and Seidel to the blue, rays. The latter effect is still more marked in photographic plates.

Prof. Silvanus P. Thompson: Poulsen's telegraphon. The telegraphon of Dr. V. Poulsen, of Copenhagen, is an apparatus which records speech or sound transmitted by telephone, and reproduces it, at any subsequent time, in another telephone. The recording is effected magnetically. In this newest pattern, a thin wire of tungsten steel is caused to run rapidly between the poles of a small electromagnet in the receiving circuit of the telephone; and this electromagnet impresses the corresponding vibrations on the wire by magnetising it in an immense series of minute local spots. The record on the wire is absolutely invisible. On passing the wire again between the poles of a small electromagnet in the circuit of a receiving tele phone, the series of minute magnetic spots on the wire sets up, by magneto-electric induction, a corresponding series of electric undulations, causing the telephone to emit a corresponding sound. The sounds so reproduced are faint unless a Brown telephone relay is employed to magnify them.

$M r . R$. Inwards: Spiraloid curve apparatus. This is an instrument consisting of a revolving table carrying the paper, and over which a pen is caused by gear-wheels and adjustable cranks to describe an undulating line, and to produce figures resembling the structure of the Diatomaceæ, Radiolaria, and other natural forms.

Mr. C. R. Darling: Experiments with liquid drops and skins. (I) Large drops of liquids may be formed in media of slightly less density, e.g. orthotoluidine in water at $18^{\circ} \mathrm{C}$. The formation is gradual, and all the stages may be observed by the unaided eye. If two drops of different diameters be made to communicate through a tube, the lesser passes into the greater when both are at the same level; if, however. the lesser drop be lowered, the movement is reversed. A position of equilibrium may be found in which both drops are stationary. (2) Skins of aniline may be formed on suitable frames under water, and made into bubbles filled with water. (3) Skins of various liquids on the surface of water exhibit characteristic movements, depending upon the liquid used.

I) r. T. K. Rose: Recrvstallisation of gold on annealing. The specimens exhibited of incompletely annealed gold show that the new crystals make their appearance singly when annealing begins, and that as the temperature is raised or the time prolonged, other

NO. 2277 , VOL. 9I] 
crystals are produced round those first formed. Some of the original crystals, which have been distorted by rolling, are completely broken up into the new smaller crystals before recrystallisation begins in other laminæ. The new crystals are soft, and the unaltered laminæ remain hard. Incompletely annealed metal thus consists of alternate strips of hard and soft material.

Prof. C. J. Patten: (I) Model illustrating the topography of the Tuskar Rock and Lighthouse relative to some features in the diurnal migration of certain birds. (2) Studies in the migratory movements of birds at the Tuskar Light-station, illustrated by a series of photographs.

The John Innes Horticultural Institution: Phenomena of plant-breeding. (I) "Maternal" hybrids and actual hybrids in Primula and Nicotiana. (2) Inheritance of double flowers and sex in Tropoeolum. (3) Inheritance in Campanula persicifolia. (4) Double flowers of various types in Begonia.

Dr. G. D. H. Carpenter: A synepigonic series of Papilio dardanus from the parent form planemoides. This exhibit represented the first proof by breeding that the form planemoides is definitely of the species Papilio dardanus.

Dr. H. F. Standing: Photographs of the skeletons of extinct giant lemurs from Madagascar, also casts of skulls of the same. This exhibit showed casts of the skulls and photographs of the mounted skeletons of two species of giant lemur recently exhumed in a subfossil condition at Ampasambazimba, in the centre of the Island of Madagascar. The smaller animal (Palaeopropithecus maximus) shows curious specialisation for an amphibious mode of life. It probably burrowed in the banks of lakes and streams; the peculiar roughened upward extension of the nasal bones no doubt carried some kind of epidermal excrescence, presumably used in burrowing. The larger animal (Megaladapis grandidieri) was arboreal in its habits, and its mode of life probably resembled that of the chimpanzee.

Prof. W. M. Flinders Petrie: Egyptian jewellery, 3400 B.c. The pectoral exhibited is of soldered gold inlaid with cut turquoise, lazuli, and carnelian, like the celebrated pectorals of Dahshur, and probably by the same artist. Found with it was a piece of inlaid open work of Senusert II., and a gold shell with soldered wire worl of Senusert III. None of this fabric has reached England before. These were found at Gerzeh, forty miles south of Cairo, in a grave in which a plunderer had been killed by a fall of the roof.

\section{REMARKABLE DROUGHT IN THE PHILIPPINES.}

THE drought experienced during the eight months, October, I9II-May, I912, probably the most severe ever observed in the archipelago. has been discussed by the assistant director of the Weather Bureau. At Manila the total rainfall recorded during the period was only 3.73 in., or a monthly average of less than half-an-inch; the driest month was April, with only $0^{\circ} 03$ in. The following rainless periods are especially noteworthy: October 24-November I6 (24 days); November 20-December I (22 days); March I9-April I2 (25 days); April I4May 7 (24 days). Deducting the insignificant amount of 0.004 in. ( $0^{\circ} \mathrm{mm}$.) on May 8 , there would result a rainless period from April $4_{4}-$ May 20 (37 days).

Sr. Coronas show's that, so far as Manila is concerned, the drought was the worst experienced since the establishment of the observatory in 1865 . From a cursory inspection of his tables it is seen that for the months October-December, IgI, the rainfall was I4.05 in. below the normal; for the months JanuaryMay, I912, 5.ro in. below, and that the total rainfall for the eight months was 5.56 in. below the absolute minimum recorded for those months during the entire period. In other regions of the archipelago the results cannot be so convincing as those for Manila, as the statistics for the secondary stations cover only a relatively short period. A table of the rainfall at twenty-six selected stations shows that it was without exception less than the normal at every station. The longest dry periods occurred in western Luzon, and the shortest on the eastern coasts of Samar and Mindanao; this was to be expected, as in the former case the dry season is most pronounced, especially from December to March, and in the latter case during the same months the most persistent rains of the whole year occur. An extraordinary period of 165 days without rain occurred at Vigan (western Luzon) between December and May.

Some very high temperatures were recorded in Aprif and May. At Manila a maximum of $100 \cdot 9^{\circ}\left(38.3^{\circ} \mathrm{C}\right.$.) occurred on May. I9; so high a temperature had not been recorded since May, 1889 . It may not be without interest to recall the fact that the drought of the summer of $\mathrm{x} g \mathrm{I}$ in this country was followed by a remarkable period of excessive rainfall during the winter six months of $19 \mathrm{I}^{-1}-\mathrm{I}$. This period has been specially discussed by Dr. Mill, and referred to in our columns.

\section{WORK OF THE ROTHAMSTED EXPERIMENTAL STATION.}

THE annual report for I9I2 of the Rothamsted Experimental Station, which has lately been issued, includes an introduction, the annual report proper, and a supplement giving the year's yields of the various series of plots. The report deals first with the season 1912 , its peculiarities, and their effect on the crops, and proceeds to give short abstracts of the work of the various members of the staff.

The central idea of the work of the Rothamsted Experimental Station is the investigation of the relation between plants and the soil in which they grow. Dr. Russell, who has during the year succeeded $\mathrm{Mr}$. Hall as director, is engaged, in conjunction with Messrs. Hutchinson, Golding, Petherbridge, and Goodey, in investigating the effects of partial sterilisation of the soil. His results have now got beyond the theoretical stage. Partial sterilisation is now practised largely in the glasshouses of the Lea valley with good results, and has so impressed the tomato and cucumber growers of that district that they are endeavouring to get established an institute for the investigation of the problems of glasshouse culturea most encouraging instance of the readiness of practical men to adopt any really sôund innovation put before them in a feasible form.

Dr. Miller continues his investigations of the nitrogen content of rainfall and drainage. Dr. Brenchley is studying the possible stimulating effects of poisons on plant growth, and has extended her survey of the weeds of arable land to the eastern counties. Mr. Davis has published the results of a carcful series of comparative determinations of potassium by the perchlorate method, which he recommends as accurate and trustworthy. The method is well worth the attention of analysts in these days of dear platinum.

The report on the whole is of great interest as showing the varied methods of attack which are being applied with success to the central problem of the relation of plants to the soil in which they grow. References are given to the original publications,

No. 2277 , VOL. 9I7 